\title{
A Diphasic Approach to Directional Locatives
}

\author{
Vivienne Fong \\ Stanford University
}

\section{Introduction}

Any theory of preposition meanings has to account for the different distributions of locatives cross-linguistically. If a type of locative preposition occurs with a class of verbs in one language, but not with the corresponding class in another, this could a priori be due to a difference in the meaning of the verb, or of the locative. Recent work in model-theoretic approaches to English preposition meaning has shown how directional locatives map their arguments onto paths, which then map onto the temporal structure of verbs (e.g., Verkuyl and Zwarts 1992, Nam 1995a,b). Verkuyl and Zwarts, for example, analyze directionality of paths as the result of an entity moving through space, yielding a particular order.

In this paper, I show that directional locatives (DLs) do not always denote paths. DLs such as 'into' and 'out of', usually interpreted as path prepositions, can denote orientation. Also, the corresponding DLs in Finnish can occur with a class of non-motion verbs such as 'forget' without expressing change in location. In both these cases, no movement is involved. I argue that DLs have a more abstract semantics than a pure spatial or temporal interpretation. DLs require only that the spatial/temporal structures they operate on have two distinct phases, and DLs are sensitive to the ordering of these phases. The analysis developed here entails a mapping of prepositional meaning onto paths which is less direct than the mapping assumed in Verkuyl and Zwart's approach, among others (cf. also Bierwisch (1988), Piñón (1993)), and in conceptual semantics (e.g., Jackendoff 1990). In addition, this analysis enables us to retain the idea that the lexical meanings of similar verb types in English and Finnish are identical.

\section{The data}

The distributions of DLs that I will account for are as follows:

(i) DLs in Finnish occur with (non-motion) verbs that entail anterior/posterior states, which is ungrammatical in English. Here, the DLs clearly do not denote paths. (1) entails that after forgetting happens, the thing forgotten remains for a time in the location denoted by the DL predicate. but it does not entail or presuppose anything about its location prior to the forgetting. A similar example with another verb ('leave'), is given in (2).

(1) Tuovi unoht-i kirja-n auto-on/ *auto-ssa.

Tuovi forget-PAST-3P book-ACC car-ILL(ative) car-INE(ssive)

'Tuovi forgot a/the book in (lit. 'into'/*in') a/the car.'

(C) 1997 by Vivienne Fong

Aaron Lawson (ed), SALT VII, 135-150, Ithaca, NY: Cornell University. 
(2) Tuovi jätt-i kirja-n auto-on/:auto-ssa.

Tuovi leave-PAST-3P book-ACC car-ILL car-INE

'Tuovi left a/the book in (lit. 'into' $\%$ ‘in') a/the car.'

In (3), 'find' entails that the thing found must be in the location prior to the finding. The same entailment holds for 'look for' (4).

(3) Tuovi löys-i kirja-n laatiko-stal *laatiko-ssa.

Tuovi find-PAST-3P book-GEN box-ELA(tive) box-INE

'Tuovi found a/the book in (lit. 'out of' $/$ “'in') a/the box.'

(4) Hän etsi-i avaint-a tasku-sta. (Karlsson 1987)

he look.for-3SG key-PAR(titive) pocket-ELA

'S/he looks for a/the key in (lit. 'out of') her/his pocket.'

In none of the cases need there be a change of location involved. The book could be in the car both before and after being forgotten or left behind. The same is true for finding and looking for something. One need not remove the object after finding it. Notice that the equivalent constructions in English are ungrammatical (5).

(5) a. Pat forgot the book in/*into the car.

b. Pat found the book in $/ *$ out of the car.

(ii) With motion verbs, DL predication gives a path reading in both Finnish and English:

(6) Kissa juoks-i huonee-stal. "Se jä-i huonee-seen.

cat run-PAST-3SG room-ELA it remain-PAST-3SG room-ILL

'A/The cat ran out of a/the room. \#It remained in the room.'

(7) Kissa hyppäs-i laatiko-stal. *Se jä-i laatikko-on. cat jump-PAST-3SG box-ELA it remain-PAST-3SG box-ILL

'A/The cat jumped out of a/the box. \#It remained in the box.'

(8) a. The cat ran out of the room. \# It remained in the room.

b. The cat jumped out of the box. \#It remained in the box.

(iii) As modifiers of concrete nouns. DLs have a spatial meaning. In (9) and (10), the DL modifier specifies the orientation of the bridge and the road, respectively, in (perspectival) space.

(9) silta San Francisco-on bridge San Francisco-ILL

'a/the bridge into San Francisco' 
(10) Because you've not got a good road into London then - unless it's this M23 quite possibly... (London-Lund)

The aim of this paper is to provide an analysis of DL meaning that will treat both the nouns and the verbs modified by the DLs in a uniform way, thus achieving an integrated semantics for DLs. In addition, the difference in English and Finnish with respect to the data in (1)-(5) must be explained.

\section{Outline of analysis}

For objects, and events which verbs denote, I will first show that they can both be seen as ordered structures that DLs can operate on. I will motivate ordered structures for times, stages of events, segments of objects, and spatial traces of events. In this way, both the nouns and the verbs which DLs modify are treated in a uniform way. Second, I adopt the concept of an interval, which contains a phase change with respect to an ordered structure of times/stages of events/parts of objects/spatial traces of events. Third, I will exploit the possibility provided by having intervals with phase changes to talk about the ordering of the two phases with respect to each other.

Let us start with times, and see how temporal phases are defined. I will take as given that time has an ordered structure, and an inherent direction. Also, time is dense. The earlier than relation $(\prec)$ between two time points is transitive, and asymmetric.

I argue that the interval over which we evaluate the truth of DL predicates consists of two phases. The notion of ADMISSIBLE PHASE-INTERVAL can be formulated according to Löbner (1989:178), who defines temporal phases as follows: 'Any admissible interval starts with a phase of not-p. and is monotone in terms of $p$ : i.e., starting with times $t$ for which $\rho(l)=()$, it may extend to later times $t^{\prime}$ with $p\left(t^{\prime}\right)=1$, but must not contain any yet later times $l^{\prime \prime}$ with $\mu\left(l^{\prime \prime}\right)=0$ again.' This is formalized in $(11)$. The interval $\left(1_{1}, t_{c}\right)$ in (i) indicates times in a half-open interval (open on the left, closed on the right).

(11) (From Löbner (1989))

$I$ is an admissible interval in terms of $\rho$ and $l$, (in short: $l \in . I\left(t_{e}, p\right)$ ) iff

(i) $\mathrm{I}=(l ;, l$,$\rfloor for some l ; \prec l$,

(ii) $I$ begins with a phase of not- $p$ :

$\exists t^{\prime} \in I \quad \forall t \in I\left(t<t^{\prime} \rightarrow \sim p(l)\right)$

(iii) the function $p$ is monotone in the interval $l$ :

for all $t . t^{\prime} \in I$, if $p$ is defined for $\iota . l^{\prime}$ then

if $t \prec t^{\prime}$ then $p(t) \rightarrow p\left(t^{\prime}\right)$

In this paper, I will in some cases deviate from the strictly $\sim p$ to p development in (11). Löbner (1989) also allows phase transition to be from positive to negative, or vice versa; the crucial point in (11) is the condition on monotonicity. 
In general terms (to be made precise below), the admissible intervals for the DLs are given in (12). Given an ordering of phases, say $\sim p \prec p$, the 'into' predicate is evaluated in the second phase, $\mathrm{p}$, while the 'out of' predicate is evaluated in the first phase $\sim$ p. What is important to note is that the Illative and Elative predicates are evaluated in opposing phases. Whether the phases are ordered $\sim \mathrm{p} \prec p$ or $\mathrm{p} \prec \sim \mathrm{p}$ is secondary.

(12) Admissible intervals for DLs:

a. 'Into'/Illative predicates take as their admissibile interval the monotone development from $\sim p$ to $p$ (or $p$ to $\sim p$ ), where the truth of LOC-IN(a)(x) is evaluated in the second phase.

b. 'Out of'/Elative predicates take as their admissible interval the monotone development from $\sim p$ to $p$ (or $p$ to $\sim p$ ), where the truth of LOC$\operatorname{IN}(\mathrm{a})(\mathrm{x})$ is evaluated in the first phase.

I will now go on to discuss how events and objects can be seen as ordered structures, and how Löbner's notion of phases can be generalized to include eventualities and spatial configurations.

\section{Events and Objects}

\subsection{Events}

Events take place in time. Following Piñón (1993), and Krifka (1989), I postulate a mapping from events to times which preserves any part structure present. In (13), the function $\tau$ (Krifka's (1989) temporal trace function of an event, or its 'run time') localizes events in time, and if is a primitive operation JOIN:

(13) $\forall \mathrm{e} \forall \mathrm{e}^{\prime}\left[\tau(\mathrm{e})-\tau\left(\mathrm{e}^{\prime}\right)=\tau\left(\mathrm{e}-\mathrm{e}^{\prime}\right)\right]$

Suppose a running event has two subevents of running as parts. What (13) says is that the result of joining the times of each subevent is identical to the join of the two subevents.

Mapping the temporal trace of an event onto the time line, which has an ordered structure, gives a pre-order of events in time. A pre-order is reflexive and transitive. This allows for the fact that different events can go on in the same period of time.

\subsection{Objects}

Can objects like bridges be treated in the same way? Jackendoff $(1992,1996)$, extending Marr's (1982) theory of encoding of object shapes, suggests that an object can be decomposed into a hierarchical arrangement of dimensions, where dimensionality is 'essentially the number of orthogonal degrees of freedom within an object.' (Jackendoff 1992:29) In this hierarchy, the primary dimension of a 
$\mathrm{road} / \mathrm{river} / \mathrm{ribbon} / \mathrm{bridge}$ is a line. Moreover, any 1-dimensional axis can have a direction or orientation. Verkuyl and Zwarts (1992) define this notion of dimensionality of an object as the number of spatial orderings that can be imposed on the material parts of that object. A bridge can be seen as one-dimensional, because it can be partitioned into a set of parts that is ordered by one spatial relation, where one slice of the bridge follows another (Verkuyl and Zwarts 1992:496). This gives a 1-dimensional view of the object, with a linear order.

Here, I first introduce a spatial trace of an object, $o$, analogous to the temporal trace in (13). In (14), the function $\sigma$ is the 1-dimensional spatial ordering of an object $o$, which localizes $o$ in space, and preserves any part structure present.

(14) (Spatial trace function):

$$
\forall \mathrm{o} \forall \mathrm{o}^{\prime}\left[\sigma(\mathrm{o}) \oplus \sigma\left(\mathrm{o}^{\prime}\right)=\sigma\left(\mathrm{o} \rightarrow \mathrm{o}^{\prime}\right)\right]
$$

Adopting the idea that a one-dimensional object can be partitioned into a set of parts (Verkuyl and Zwarts 1992), the spatial trace function can give the parts of the bridge $\left(\mathrm{s}_{1}, \mathrm{~s}_{2}\right.$, etc $): \mathrm{s}_{r}=\sigma\left(\mathrm{b}_{x}\right)$.

Second, I postulate that an object construed as being 1-dimensional can have an orientation or direction. This will be discussed below.

\subsection{Phases for objects}

Objects like bridges are easy to view as consisting of phases. The viewing of objects as 1-dimensional entities, and the spatial trace function (see (14)) allow us to look at a bridge as consisting of parts, as discussed above. The parts of the bridge which are outside of a region - for example, San Francisco - can be 1 phase (call it $\sim p$ ) and the part of the bridge that is within San Francisco is the other (p) (see (15)). In other words, phases are defined in terms of locations occupied by the parts of the bridge as it spans out in space.

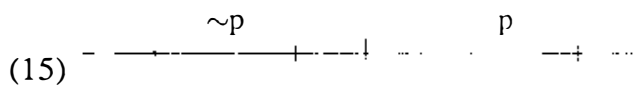

We derive the ordering of phases from knowing the location of San Francisco in relation to parts of the bridge and a given narrative perspective. Bridges are inherently a-directional. A bridge has no intrinsic front/back, or left/right coordinate system of its own, and whether it can be called a bridge 'into San Francisco' or 'out of San Francisco' depends on the narrator's/speaker's perspective in fixing the point of origin of the bridge. With at bridge out of San Francisco', the point of origin is fixed at San Francisco. and the part of the bridge that is located in San Francisco is ordered before the part located outside of the city. With 'a bridge into San Francisco', the point of origin is fixed outside of San Francisco, and the part of the bridge that is located in San Francisco is ordered after the part located outside of the city.

Imagine a bridge that straddles the San Francisco Bay, with one end in San Francisco. Let $\mathrm{p}$ be the location predicate applying to San Francisco, LOC-IN(san francisco): 
(16) $\mathrm{p}\left(\mathrm{s}_{x}\right)=1$ iff:

$\exists \mathrm{b}_{x}\left[\mathrm{~s}_{x}=\sigma\left(\mathrm{b}_{s}\right) \wedge\right.$ LOC-IN $($ san francisco $\left.)\left(\mathrm{b}_{x}\right)\right]$

And suppose we order the phases $\mathrm{p}$ and $\sim \mathrm{p}$ as follows: $\sim \mathrm{p} \prec \mathrm{p}$. This is depicted in (17a) with the axis pointing to San Francisco.

(17)

a. 'into' San Francisco:
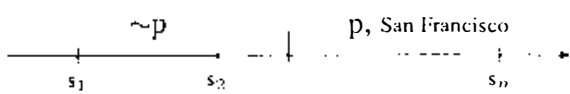

b. 'out of' San Francisco:

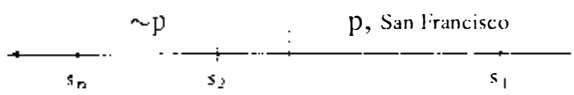

Now, the ordering in (17a) gives the admissible interval $I$ (in terms of $\mathrm{p}$ and $\mathrm{s}$ ) over which we can evaluate silta San Franciscoon/bridge into San Francisco (see (18). We have an interval in which there is a monotonic phase change from $\sim p$ to $p$, and the truth of directional locative predicate can be evaluated in the second phase.

(18) $I$ is an admissible interval in terms of $p$ (LOC-IN(san francisco)) and $s$ iff

(i) $\mathrm{I}=\left(s_{i}, s_{\epsilon}\right]$ for some $s_{i} \prec s_{\epsilon}$

(ii) $I$ begins with a phase of not-p):

$\exists s^{\prime} \in I \forall s \in I\left(s \prec s^{\prime} \rightarrow \sim p(s)\right)$

(iii) the function $p$ is monotone in the interval $I$ :

for all $s, s^{\prime} \in I$, if $p$ is defined for $s . s^{\prime}$ then

if $s \prec s^{\prime}$ then $p(s) \rightarrow p\left(s^{\prime}\right)$

I will assume here that the semantics of both the Finnish and English expressions are the same, hence I will define the truth conditions just for 'a bridge into San Francisco' in (19).

(19) a. a bridge into San Francisco

b. $\exists$ a(bridge(a)) and

(i) $I$ is an interval, which is an ordering of the range of $\sigma(a)$, and contains one phase change $(\sim p \prec p)$ with respect to the location of some part of the bridge in San Francisco: and

(ii) $\exists \mathrm{s} \in \mathrm{I} \forall \mathrm{y} \in \mathrm{I}(\mathrm{y} \prec \mathrm{s} \rightarrow \neg \mathrm{LOC}-\mathrm{IN}(\mathrm{y}, \mathrm{san}$ francisco $)) \wedge$

$\exists \mathrm{s}^{\prime} \in \mathrm{I} \forall \mathrm{z} \in \mathrm{I}\left(\mathrm{s}^{\prime} \prec \mathrm{z} \rightarrow \mathrm{LOC}-\mathrm{IN}(\mathrm{z}\right.$, san francisco $)$ )

Condition (i) is satisfied by having a well-defined admissible interval, as given in (18), that is, there is one and only one phase change. Condition (ii) says that if one part, $y$, of the bridge, is early enough in the ordering, it should be located outside 
of San Francisco, and a later part, z, if it is late enough in the ordering, should be in San Francisco. This condition ensures that the bridge that we are talking about is neither wholly outside of San Francisco, nor wholly inside, but rather, the bridge has to straddle the two regions.

Conversely, bridge out of San Franciscolsilta San Franciscosta would have the ordering of phases $\mathrm{p} \prec \sim p$, if we keep $p$ as the location predicate applying to San Francisco. The ordering is different because the perspective is switched - see (17b), where the axis points away from San Francisco. So, we would evaluate the truth of the Elative predicate at p (see (16)), which is now the first of two phases.

(20) a. a bridge out of San Francisco

b. $\exists$ a(bridge(a)) and

(i) $I$ is an interval, which is an ordering of the range of $\sigma(\mathrm{a})$, and contains one phase change ( $p \prec \sim p$ ) with respect to the location of some part of the bridge in San Francisco; and

(ii) $\exists \mathrm{s} \in \mathrm{I} \forall \mathrm{y} \in \mathrm{I}(\mathrm{y} \prec \mathrm{s} \rightarrow \mathrm{LOC}-\mathrm{IN}(\mathrm{y}$, san francisco $)) \wedge$

$\exists \mathrm{s}^{\prime} \in \mathrm{I} \forall \mathrm{z} \in \mathrm{I}\left(\mathrm{s}^{\prime} \prec \mathrm{z} \rightarrow \neg \mathrm{LOC}-\mathrm{IN}(\mathrm{z}\right.$, san francisco $\left.)\right)$

In this account, the meaning of DLs is not tied to the idea of fictive motion (cf. Matsumoto (1996a, 1996b), Talmy (1996), Langacker (1987), among others). Fictive motion is invoked by the authors mentioned for linguistic expressions that do not express a real, physcial motion of the Subject, but rather some sort of subjectively conceptualized notion of motion. For example, in the examples below (from Talmy (1996)), the road/the mountain range is depicted as 'moving'.

(21) a. This road goes from Modesto to Fresno.

b. That mountain range goes from Mexico to Canada.

But note that the examples in (9) and (10) do not involve motion verbs. Also, as modifiers of nouns, the orientational reading of the DLs in (9) and (10) cannot be attributed to stative verbs inducing the stative/orientational interpretation (cf. Nam $(1995 a, b))$. Consider the examples below. where directional locatives like across and through can give a stative reading when they occur with stative verbs:

(22) a. The cat is sitting across the street.

b. Chris saw the cat through the window.

Since the data in (9) and (10) involve neither verbs of motion nor stative verbs, this account of DLs provides an interpretation that is confined within the domain of objects.

Finally, the proper interpretation of noun phrases with DL modifiers will have to take into account the use of these expressions. For example, while a road that has a phase in San Francisco and a phase outside of it can be called a road into San Francisco, the same road, if it leads to a toll-booth before entering San Francisco is 
not usually termed a road into the toll-booth, presumably because roads are usually not seen as helping one to (merely) end up at a toll-booth. Similarly, a ribbon into the city may seem anomalous, but if a context is provided where the ribbon has some function/use, for example, for ants to crawl on, then the phrase is acceptable.

Below, I show that the present analysis based on phases relates orientation and path structure in a uniform way.

\subsection{Phases for motion verbs}

I have already discussed how events take place in time, and how events can be mapped onto times, given the temporal trace function. But in addition, motion events are closely related to space as well. An entity in motion moves through time, passing through points in space. In other analyses of motion events (Bierwisch 1988, Verkuyl and Zwarts 1992, Piñón 1993. Nam 1995a,b, inter alia), the spatiotemporal mapping of motion events is what defines the canonical notion of Path.

In Verkuyl and Zwarts (1992), for example, a prepositional phrase headed by 'to' is interpreted as an atemporal spatial path $P_{t,}=\left\langle p_{1}, \ldots p_{i}, \ldots, p_{s}\right\rangle$. Motion events involve a GO function, which provides a temporal structure $\left\langle t_{1}, \ldots t_{i}, \ldots\right\rangle$. The application of the GO function to the spatial path will be a mapping from the atemporal spatial Path into the temporal Path, creating a new spatiotemporal path $\left\langle\left(\mathrm{t}_{1}, \mathrm{p}_{1}\right), \ldots\left(\mathrm{t}_{i}, \mathrm{p}_{i}\right), \ldots\right\rangle$.

But in the present analysis, it would be wrong to assume that the DLs under consideration refer to paths directly, since with objects and non-motion verbs, no change of location is involved. What we need first is the spatial trace of a motion event. I use a simplified spatial trace function $\sigma_{c}$, which locates events in space, and preserves any part structure present:

(23) (Spatial trace of events):

$$
\mathrm{S}_{x}=\sigma_{e}\left(\mathrm{e}_{x}\right) \text {, where } \forall \mathrm{e} \forall \mathrm{e}^{\prime}\left[\sigma_{\epsilon}(\mathrm{e}) \cdots \sigma_{r}\left(\mathrm{e}^{\prime}\right)=\sigma_{r}\left(\mathrm{e}: \mathrm{e}^{\prime}\right)\right]
$$

We already have a temporal trace function $\tau$ for events. The application of the temporal function to the spatial mapping will result in a space/time mapping of motion events (the same result as that of Verkuyl and Zwarts (1992)).

Given that we have an ordering of space/time coordinates, the admissible interval for motion events is defined in terms of the change in location of the entity moving through time.

For motion into a room, for example. the part of the spatiotemporal trace of the motion event that occurs outside the room can be one phase (call it $\sim p$ ), and the part that is within the room can be another $(p)$. The ordering of phases is $\sim p \prec p$.

(24) Order of phases for 'dancing into the room': $\sim p \prec p$.

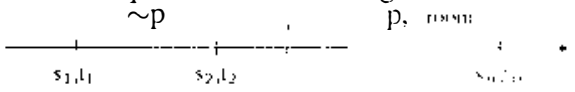

The truth condition for 'into the $\operatorname{room}(\mathrm{Pat})$ ' is evaluated at $\mathrm{p}$ : 
(25) $\mathrm{p}\left(\mathrm{s}_{x}, \mathrm{t}_{x}\right)=1$ iff:

$\exists \mathrm{e}_{x}\left[\mathrm{~s}_{x}=\sigma_{e}\left(\mathrm{e}_{x}\right) \wedge \mathrm{t}_{x}=\tau\left(\mathrm{e}_{x}\right) \wedge\right.$ LOC-IN (room) $($ Pat $\left.)\left(\mathrm{e}_{x}\right)\right]$

The interpretation of a sentence like 'Pat danced into the room', abstracting away from tense, is given below:

(26) a. Pat dance into the room.

b. $\exists e($ Dance(Pat,e) $)$ and

(i) $I$ is an interval which is an ordering of the range of $\left(\tau(\mathrm{e}), \sigma_{f}(\mathrm{e})\right)$, and contains one phase change $(\sim p \prec p)$ with respect to the location of Pat in the room at some time; and

(ii) $\exists(\mathrm{s}, \mathrm{t}) \in \mathrm{I} \forall(\mathrm{a}, \mathrm{b}) \in \mathrm{I}((\mathrm{a}, \mathrm{b}) \prec(\mathrm{s}, \mathrm{t}) \rightarrow \neg \mathrm{LOC}-\operatorname{IN}($ Pat,room, (a,b)) $) \wedge$

$\exists\left(\mathrm{s}^{\prime}, \mathrm{t}^{\prime}\right) \in \mathrm{I} \forall(\mathrm{x}, \mathrm{y}) \in \mathrm{I}\left(\left(\mathrm{s}^{\prime}, \mathrm{t}^{\prime}\right) \prec(\mathrm{x}, \mathrm{y}) \rightarrow\right.$ LOC-IN $($ Pat,room, $\left.(\mathrm{x}, \mathrm{y}))\right)$

I do not claim that all dancing motions have a trajectory yielding this ordering of positions. Dancing can well trace random lines/curves in space. and yet not have a trajectory that gives a change of location from $\sim p$ to $p$. However, all we need is this: if dancing involves a trajectory, we get the right structures for defining possible phases; and DLs can only be interpreted given this particular structure. Therefore, the analysis predicts that when dancing has some other configuration, the event is incompatible with DL interpretation.

A related issue (also raised by Löbner (1989)) is that given the definition of admissible intervals as being monotone in terms of $\mathrm{p}$, a dancing event (for example, dancing a tango) that involves going in and out of the room, or that involves backtracking, will have to be ruled out in this model. In such cases, the entire event is correctly predicted to be incompatible with the description 'dancing into the room'. But if we allow the event to be broken down into small enough chunks, that is, if we relativize the points in space/time where there is a trajectory involving one phase change, then that smaller event chunk can be described with the DL. Witness the well-formed description with a DL predicate in (27), in a context where a couple dances the tango all over the house, going in and out of various rooms:

(27) While performing the tango in the house, the couple danced into the kitchen.

Let us look briefly at 'dancing out of the room'. Keeping the phases p as location inside the room, and $\sim p$ as location outside the room, the ordering of phases is $\mathrm{p} \prec \sim \mathrm{p}$. And the truth condition for 'out of the room' is evaluated at $\mathrm{p}$.

(28) Order of phases for 'dancing out of the room': $p \prec \sim p$

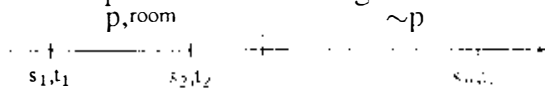

The ordering of spatial positions, and also the ordering of phases, are dependent on the progression of the motion event through time. One logical consequence of the spatiotemporal mapping of motion events pursued here is that two expressions 
such as 'dancing into the kitchen' and 'dancing out of the (same) kitchen' cannot describe the same event in a given time interval. That is, at a given time $t$, the kitchen cannot be both a phase $\mathrm{p}$ and a phase $\sim p$, in our model. Rather, the two expressions must be interpreted either as (i) describing consecutive events: for example, dancing into the kitchen at time $t$, and dancing out of the kitchen at time $t^{\prime}\left(t \prec t^{\prime}\right)$; or (ii) describing two separate events (with different participants) that take place at the same time $t$, given our assumption that the mapping of events onto time gives a pre-order of events in time (section 4.1).

On the other hand, recall that the axis representing the spatial ordering of parts of objects has two possible directions, depending on the perspective taken. "A bridge into San Francisco' and 'a bridge out of San Francisco' can describe the same bridge, depending on the perspective taken. The bridge has no temporal mapping, and so perspective shift can occur at any point. But perspective shift cannot be invoked for the manner-of-motion events described above. Thus the present analysis captures the difference between the use of DLs as modifiers of nouns, and as modifiers of motion events.

\subsection{Event structures}

We now come to verbs that have posterior, or anterior, entailed states, such as 'forget' and 'find', respectively. How do we motivate the appropriate phases over which to interpret Finnish DLs when they occur with these verbs?

This class of verbs, like motion verbs, denote events that can be given a temporal trace. But they differ from motion verbs in two important ways. First, they do not denote motion, so there is no movement through space, and thus there will be no spatial trace of the argument of the DL predicate. Second, these verbs are culminated events (Moens and Steedman 1988. Steedman 1997). A verb like 'forget' is a typical culminated event, with an entailed consequent state. So these verbs have a different lexical aspectual representation from motion verbs, which are processes.

The phases for interpreting DLs with verbs like 'forget' and 'find' cannot be defined in spatial terms in the same way as for objects and motion events, because there is no spatial trace over time/space. Instead, I argue that Finnish DLs can also be interpreted in phases defined in terms of aspectual development or transition.

The aspectual structure of a verb like 'forget', for example, consists of the event, and a consequent state. The culmination of the event can be seen as the transition point from one state of affairs to a conseguent state. We can consider the consequent state of a forgetting event as a phase $\mathrm{p}$, where there is no longer any potential change of location of the thing forgotten, so the consequent state maintains the position of the book. Supporting evidence for this interpretation of the semantics of 'forget' comes from temporal adverbials which "specify the time that the result of the action obtained' (Dowty 1979:251), as shown in (29) for both English and Finnish: 
b. Unohd-i-n kaku-n uuni-in kahde-ksi tunni-ksi. forget-PAST-1P cake-ACC oven-ILL two-TRA(nslative) hour-TRA 'I forgot the cake in the oven for two hours.'

Prior to forgetting, however, there is still potential for acting on/doing something with the book, so to speak. Let us call this anterior phase $\sim p$. So, the culmination of 'forgetting' is a transition between a phase with potential for change, and a second phase with no potential for change. We now have an interval $I$ that has exactly one phase change with respect to the aspectual structure of forgetting. The phases can be defined in terms of the temporal trace of the aspectual properties of the verb - I will simply label the aspectual semantic property of verbs as ' $A$ ' (see (30)). The temporal trace function $\tau$ relates what is a prior and a consequent state of affairs as time-points on a time-line. And because the event of forgetting is a culminated process, the time of forgetting is represented as a point on the time line (the culmination point), within the interval in which we can talk about the aspectual property of the verb (see (31)).

(30) $\mathrm{t}_{x}=\tau\left(\mathrm{A}_{x}\right)$

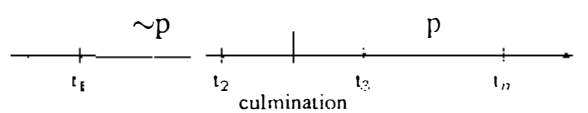

The Illative predicate is evaluated at $\mathrm{p}$ (see (32)). The truth condition for 'Pat forgot the book car-ILLATIVE', abstracting away from tense, is given in (33).

(32) $\mathrm{p}\left(\mathrm{t}_{x}\right)=1$ iff:

$\exists \mathrm{A}_{x}\left[\mathrm{t}_{x}=\tau\left(\mathrm{A}_{x}\right) \wedge\right.$ LOC-IN $\left(\right.$ book,car, $\left.\left.\mathrm{t}_{x}\right)\right]$

(33) a. Pat forget the book car-ILlative

b. $\exists$ e(Forget(Pat,book,e) $)$ and

(i) $I$ is an interval, which is an ordering of the range of $\tau(\mathrm{A})$, and contains one phase change $(\sim p \prec p)$ with respect to the potential change of location of the book; and

(ii) $\exists \mathrm{t} \in \mathrm{I}\left(\mathrm{LOC}-\mathrm{IN}(\right.$ car,book,t $) \wedge \forall \mathrm{t}^{\prime} \in \mathrm{I}\left(\mathrm{t} \prec \mathrm{t}^{\prime} \rightarrow \mathrm{LOC}-\mathrm{IN}\left(\right.\right.$ car,book, $\left.\left.\left.\mathrm{t}^{\prime}\right)\right)\right)$

'Forget' does not presuppose anything about the location of the book prior to the culmination of the event. What (33bii) salys is that given a time t within the admissible interval when the book is located in the car, we know that for all times following $t$, the book will be in the car.

Conversely, the aspectual structure of a verb like 'find' consists of the event, and an anterior entailed state of affairs, that is, the book must be in that location prior to being found. The culmination of the event can be seen as the transition point from this anterior state to another state of affairs. In terms of potential for change, prior to finding the book, there is no potential for changing the location of the book, but after finding it, there is a potential of removing it. Given that the culmination of the 
'finding' event is the transition point, we can see two phases, the first phase $\mathrm{p}$ where there is no potential for change, and the second phase $\sim p$ where there is potential for change.

(34) a. Pat find the book car-Elative

b. $\exists e($ Find(Pat,book,e $)$ ) and

(i) $I$ is an interval, which is an ordering of the range of $\tau(\mathrm{A})$, and contains one phase change $(p \prec \sim p$ ) with respect to the potential change of location of the book; and

(ii) $\exists \mathrm{t} \in \mathrm{I}\left(\mathrm{LOC}-\mathrm{IN}(\right.$ car,book,t $) \wedge \forall \mathrm{t}^{\prime} \in \mathrm{I}\left(\mathrm{t}^{\prime} \prec \mathrm{t} \rightarrow \mathrm{LOC}-\mathrm{IN}\left(\mathrm{car}\right.\right.$, book, $\left.\left.\left.\mathrm{t}^{\prime}\right)\right)\right)$

'Forget' only occurs with Illative/Allative predicates, and 'find' only with Elative/Ablative predicates. This falls out from our modelling of the phases based on the inherent entailment properties of the verbs. The Illative predicate only gets an interpretation in a second phase $\mathrm{p}$, when $\mathrm{p}$ is well-defined by the posterior entailment property of 'forget'. The Elative predicate only gets an interpretation in a first phase $\mathrm{p}$, when $\mathrm{p}$ is well-defined by the entailment property of 'find'.

In summary, Finnish DLs can be interpreted in the phases determined by the temporal trace of the lexical aspectual structure of verbs. I assume that English DLs, on the other hand, can only access phases that are defined spatially, or spatiotemporally, and therefore do not occur with verbs like 'forget' and 'find' which do not have mappings of structures in space.

\section{Predictions}

Supporting evidence for this treatment of Finnish DLs comes from the occurrence of DLs with various classes of verbs that share similar aspectual structures as the verbs 'forget' and 'find'.

First, consider aspectual verbs like ruveta 'begin', and lakata 'stop'. Aspectual verbs that describe the onset of an event (e.g., 'begin', 'start') describe the action of turning the event on (i.e., a transition terminating its off-state and starting an on-state of the same type) (ter Meulen 1995). In Löbner's (1987) phase-semantic account, 'begin' and 'stop' refer to an implicit time parameter $t^{\circ}$ (which may differ from the time of utterance, because of tense operators, for example), and 'these verbs tell something about the close future, how things go on from $t^{\circ}$ with respect to the proposition embedded' (Löbner 1987:73). The relevant time interval has two phases, $\sim p$ and $p$, which contain $t^{\circ}$. For $\operatorname{stop}\left(p, t^{\circ}\right)$, the first phase is $p$ and has started before $t^{\circ}$. If $t^{\circ}$ is the last point of this phase, then $\operatorname{stop}\left(p, t^{\circ}\right)$ is true.

In Finnish, aspectual verbs like ruveta and lakata take verbal complements that are suffixed with DL Case. 'To begin reading' has an anterior phase where no reading occurs, and a transition point starting the reading phase. So the phases here are defined over the temporal-aspectual mapping of 'begin'.

(35) Toini rupea-a luke-ma-an.

Toini begin-3SG read-INF-ILL

'Toini begins reading (lit. 'Toini begins into reading').' 
(36)

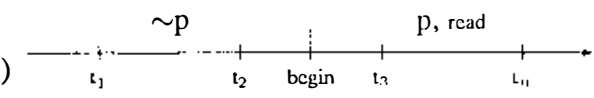

'To stop reading', on the other hand, presupposes a posterior phase of reading, then the point of stopping is a transition point, which is followed by a phase where there is no reading.

(37) Toini lakka-a luke-ma-sta.

Toini stop-3SG read-INF-ELA

Toini stops reading (lit. 'Toini stops out of reading').

Notice that the Illative occurs with 'begin', and the Elative occurs with 'stop'. This is similar to the patterning with 'forget' and 'find'. In the discussion above, I argued that the Illative predicate only gets an interpretation in the second of two phases (phase p), when $p$ is well-defined by the entailment property of 'forget' (entailing a posterior state of affairs). Here, the Illative predicate gets an interpretation in the second of two phases (phase $\mathrm{p}$ ), when $\mathrm{p}$ is well-defined by the temporal aspectual mapping of 'begin', which describes the start, and continuation thereafter, of a reading event. The Elative predicate gets an interpretation in the first of two phases, when the first phase is well-defined by the temporal aspectual mapping of 'find' and 'stop'.

Second, verbs of exhortation like kehoittaa 'encourage', neuvoa 'advise', kieltää 'forbid', and varoittaa 'warn', are intended to bring about a change in another person's actions or intentions. Notice once again the different selections of Illative or Elative predicates by these verbs:

(38) Sointu kehoitt-i Toini-a laula-ma-an. Sointu encourage-PAST-3P Toini-PAR sing-INF-ILL

'Sointu encouraged Toini to sing.'

(39) Sointu neuvo-i Toini-a lähte-mä-än. Sointu advise-PAST-3P Toini-PAR leave-INF-ILL

'Sointu advised Toini to leave.'

(40) Sointu kiels-i Toini-a poltta-ma-sta.

Sointu forbid-PAST-3P Toini-PAR smoke-INF-ELA

'Sointu forbade Toini to smoke.'

(41) Sointu varoitt-i Toini-a lähte-mä-stä.

Sointu warn-PAST-3P Toini-PAR leave-INF-ELA

'Sointu warned Toini against leaving.'

The distribution of Elative versus Illative predicates here can be understood in terms of the interpretations of speech act verbs and their complements. I will merely sketch out the possible interpretations in order to illustrate the idea of phases here; 
for more detailed discussion, see Wierzbicka (1988) and Rohrbaugh (1995), among others. For kieltää 'forbid' and varoittaa 'warn', the speaker removes an initial set of options available to the addressee, but the verbs do not carry any expectations as to what might happen next. The verb suffixed with Elative Case in (40) and (41) is a predicate that refers to the initial option (for our purposes, the first phase). In the case of kehoittaa 'encourage' and neuvoa 'advise', the speaker considers 'a future action of the addressee' (cf. Wierzbicka 1988:36ff), but the initial set of options available is irrelevant. The Illative verbal predicate in (38) and (39) refers to this 'future action' (in the second phase).

Third, in Finnish, there is a difference in meaning between the verbs jäädä (which I gloss as 'remain') and pysyä 'stay'. This is reflected in the locative predicates that the verbs select: jäädä takes DL predicates (42), while pysyä does not (43).

(42) Neva-n suu jă-i Täyssinä-n rauha-ssa Neva-GEN mouth remain-PAST-3SG Täyssinä-GEN treaty-INE venäläis-i-lle. Russian-PL-ALL(ative)

'In the Treaty of Täyssinä the mouth of the Neva went to the Russians.' (Perhaps the Neva changed hands.)

(43) Neva-n suu pysy-i Täyssinai-n rauha-ssa

Neva-GEN mouth stay-PAST-3SG Täiyssinä-GEN treaty-INE

venäläis-i-llä.

Russian-PL-ADE(ssive)

'In the Treaty of Täyssinä the mouth of the Neva stayed in the possession of the Russians.' (There was no change of hands.)

In (42), there is a possibility that the Russians might not have had claims on the River Neva before the treaty, and after the treaty, they definitely did. This is captured by the DL predicate (the Allative). On the other hand, (43) with pysyä does not presuppose any change could have taken place, and so, we cannot postulate any phases where there might be a change. As such, DL predicates do not occur with such a verb.

\section{Conclusion}

The meanings of English DLs have always been noted to encode a meaning of change (Dowty 1979, Jackendoff 1990. Wunderlich 1991). The question for such an interpretation is how orientation meanings can come about. Finnish DLs can be seen as lacking a change meaning, and therefore they can occur with verbs that do not denote change (Fong 1997). The question for this approach is how these locatives can occur with motion verbs to denote change of location.

I have shown that the diphasic approach to the interpretation of DLs presented here gives a uniform treatment of the meaning of DLs in cases where Finnish and 
English behave the same (i.e., with motion verbs and objects). In addition, I have shown that Finnish differs from English in allowing the interpretation of DL predicates in non-spatial domains.

What DLs are sensitive to is the order of things: whether states of affairs precede or follow events, whether the point of view regards one piece of object as preceding or following another.

\section{Acknowledgements}

I wish to thank Arto Anttila, Cleo Condoravdi, Martina Faller, Brett Kessler, Paul Kiparsky, Rob Malouf, Stanley Peters, Chris Piñón, and especially Henriëtte de Swart, for comments, suggestions, and help. I also thank the audience at SALT VII for their comments.

\section{References}

Bierwisch, Manfred. 1988. On the Grammar of Local Prepositions. In Syntax, Semantik und Lexikon, ed. Manfred Bierwisch, Wolfgang Motsch, and Ilse Zimmermann. Berlin: Akademie-Verlag.

Dowty, David R. 1979. Word Meaning and Montague Grammar. Dordrecht: Reidel.

Fong, Vivienne. 1997. A Temporal Interpretation for Locative Case. Proceedings of WCCFL 15:145-159.

Jackendoff, Ray. 1990. Semantic Structures. Cambridge, Mass.: MIT Press.

Jackendoff, Ray. 1992. Parts and Boundaries. In Lexical and Conceptual Semantics, ed. Beth Levin and Steven Pinker. Cambridge, Mass.: Blackwell.

Jackendoff, Ray. 1996. The Proper Treatment of Measuring Out, Telicity, and Perhaps Even Quantification in English. Natural Language and Linguistic Theory 14:305-354.

Karlsson, Fred. 1987. Finnish Grammar. Porvoo: Werner Söderström Osakeyhtiö. 2nd edition.

Krifka, Manfred. 1989. Nominal Reference, Temporal Constitution and Quantification in Event Semantics. In Scmantics and Contextual Expressions, ed. Renate Bartsch, Johan van Benthem, and Peter van Emde Boas. Dordrecht: Foris.

Langacker, Ronald. 1987. Foundations of Cognitive Grammar. Stanford, California: Stanford University Press.

Löbner, Sebastian. 1987. Quantification as a Major Module of Natural Language Semantics. In Studies in Discourse Representation Theory and the Theory of Generalized Quantifiers, ed. Jeroen Groenendijk, Dick de Jongh, and Martin Stokhof. Dordrecht: Foris.

Löbner, Sebastian. 1989. German sc/hm-erst-noch: An Integrated Analysis. Linguistics and Philosophy: 12:167-212.

Marr, David. 1982. Vision. San Francisco, California: Freeman. 
Matsumoto, Yo. 1996a. How Abstract is Subjective Motion? A Comparison of Access Path Expressions and Coverage Path Expressions. In Conceptual Structure, Discourse, and Language, ed. Adele Goldberg. Stanford: CSLI Publications.

Matsumoto, Yo. 1996b. Subjective Motion and English and Japanese Verbs. Cognitive Linguistics 7:183-226.

Moens, Marc, and Mark Steedman. 1988. Temporal Ontology and Temporal Reference. Computational Linguistics 14:15-28.

Nam, Seungho. 1995a. The Semantics of Locative Prepositional Phrases in English. Doctoral dissertation, UCLA.

Nam, Seungho. 1995b. The Semantics of Paths and Spatial Orientations. Proceedings of the 10th Amsterdam Colloquium 551-566.

Piñón, Christopher J. 1993. Paths and Their Names. Proceedings of CLS 29:287303.

Rohrbaugh, Eugene Grant II. 1995. Scalar Interpretation in Deontic Speech Acts. Doctoral dissertation, University of Texas at Austin.

Steedman, Mark. 1997. Temporality. In Handbook of Logic and Language, ed. Johan van Benthem and Alice ter Meulen. Amsterdam: Elsevier Science.

Talmy, Leonard. 1996. Fictive Motion and 'Ception'. In Language and Space, ed. Paul Bloom, Mary A. Peterson, Lynn Nadel, and Merrill F. Garrett. Cambridge, Mass.: MIT Press.

ter Meulen, Alice G. B. 1995. Representing Time in Natural Language: The Dynamic Interpretation of Tense and Aspect. Cambridge, Mass.: MIT Press.

Verkuyl, Henk J., and Joost Zwarts. 1992. Time and Space in Conceptual and Logical Semantics: the Notion of Path. Linguistics 30:483-511.

Wierzbicka, Anna. 1988. The Semantics of Grammar. Amsterdam: John Benjamins.

Wunderlich, Dieter. 1991. How do Prepositional Phrases fit into Compositional Syntax and Semantics? Linguistics 29:591-621. 